\title{
Measuring Impact of Big Five Personality Traits on Team Performance: A Case of Habib Metro Bank, Karachi
}

\author{
Farhana Nazir $^{1 *} \quad$ Farhan Ahmed $^{1} \quad$ Ifrah Azmat $^{1} \quad$ Farid Zafar $^{2} \quad$ Dr. Sarfaraz Ahmed Shaikh ${ }^{3 *}$ \\ 1.Shaheed Zulfikar Ali Bhutto Institute of Science \& technology, SZABIST Karachi, Pakistan \\ 2.Dubai Islamic Bank, Karachi, Pakistan \\ 3.Indus Center for Sustainable Development, Karachi, Pakistan
}

\begin{abstract}
Different types of personalities in the Big Five Personality Model have an immense impact on performance of the team. Human resource supervisors must be capable to categorize person conducts as well as qualities as a result they can comprehend employees' diverse persona. Persona is a reasonably firm set of distinctiveness that manipulates a person's behavior. This persona should to be implicit so that the organization can utilize their apparent qualities along with talents in the right work and path. Our study is about the impact of Big Five Personality Traits Model on Team Performance. It has a quantitative nature. Self-selection and non-probability convenience sampling were used to determine the sample size. When an analysis as carried out it was concluded that Extraversion, conscientiousness, and agreeableness were found to have significant as well as positive correlation with the performance of the team. Openness to experience and neuroticism was found to have insignificant correlation with the team performance. Through our research an organization's manager will be able to the type of personality an employee possesses and how much it will affect the performance of the group as a whole. As result of conducting analyses we came to know that employees with diverse persona can perform well in a team.
\end{abstract}

Keywords: Team performance, apparent qualities, Personality

DOI: $10.7176 / \mathrm{DCS} / 9-2-06$

\section{Introduction}

1.1 Background:

Performance is the crucial to achievement in such a competitive situation. In this way companies are different from one another. This is why in today's viable corporate situation establishments wanting full output from their employees. In contemporary ages it is appreciated that numerous establishments reinvented their effort through practice of group (Barrick, Bradely, Amy, Kristof, \& Colbert, 2007). Altogether participants are jointly responsible for the consequences in a group. Participants in a group are interrelated with each other. The accomplishment or disappointment of team is depending upon the excellence of their combined effort. Working in teams gives more efficient performance as compared to individual performance. Due to this reason, establishments are concentrating on spending groups rather than one entity to accomplish determined yield indispensable for their existence. In several establishments groups are progressively used with favorable outcomes. The capability to work efficiently on a group is decidedly appreciated by establishments, in accumulation to articulation and diagnostic abilities. (Thomas, Sarah, \& Busby, 2003). Employees functioning as a group headed for a mutual objective attain more than if they work unaided (W \& Jhonson, 1999). Cooperation among employees can direct to inherent enthusiasm, augmented diligence, and countless transmission of expertise (Pfaff, Elizabeth, \& Huddleston, 2003). Improvement is frequently glinted by cooperation encompassing the joining of various corrections (Andrew \& Hargadon, 2003). Persona is mainly amalgamation of responses, approaches and actions. Persona encompasses dissimilar division of opinions, spirits and activities that create individual unique. Persona qualities are universally considered as imperative unique elements in collaboration and group enactment. There are various persona assessments in presence, but a generally acknowledged experiential representative in the communal disciplines is entitled as Big-Five, or homogenously the Five-Factor Representation (FFM) (Srivastava, 2011). FFM defines a categorization of five persona areas which plan individualities that are interrelated. These areas are: assertiveness, sociability, meticulousness, neuroticism and openness. The FFM is built upon broad, organized, and severe experimental work, and is deliberated further practicable as a representation of persona than the renowned Myers-Briggs personality (McCrae, R, \& John, 1992). The appearance of the Five aspect representation of persona (Norman W. T., 1963) or the "Big Five" (Goldberg L. R., 1990), gives an apparent theoretical in addition to measurement structure for study into traits (Robertson I. a., 1998). His five features - gregarious, amiableness, dutifulness, uneasiness, and exposure - remained initiated to constantly explain persona intended for a variety of illustrations (Hofstee, 1998) (McCrae R. R., 1997). Extraversion means the degree to which an individual is sociable and conversational and is linked with conducts for instance being friendly, companionable, confident, and vigorous. (McCrae R. R., 1985). Agreeableness means the degree to which a human being is supportive along with gracious. Extremely agreeable individuals' exhibit actions for example being well-mannered, flexible, credulous, helpful, for bearing, 
sympathetic, also broadminded (McCrae R. R., 1985).Conscientiousness means the level to which a human being is nature-denying as well as prepared. Related actions are being cautious, methodical, accountable, prearranged, planned, reliable, accomplishment oriented, as well as persistent (McCrae R. R., 1985). Sentimental strength means extent towards that an individual is peaceful, balanced, as well as protected. The contradictory is identified as neuroticism, which is connected with actions such as being concerned, disheartened, irritated, uncomfortable, and emotive, concerned, plus unconfident (McCrae R. R., 1985). Lastly, exposure explains degree towards that an individual is creative as well as inquiring. Extremely open people can be depicted as being sophisticated, unique, activist, intellectual, as well as creatively responsive (McCrae R. R., 1985).

\subsection{Problem Statement:}

Now day's organizations are attentive to the significant characters of individual traits in the workplace because personality characteristics are key factors in endorsing teamwork and team performance/group enactment. Hence, to select appropriate workforce many of the enrollment procedures assess individual dissimilarities. Our study will figure out the impact of big five persona characteristics on team performance of employees from Habib Metro Bank

\subsection{Research Question:}

-What are the effects of big five personality traits on team performance?

\subsection{Objectives:}

-To analyze consequence of extraversion on team performance

-To analyze the effect of agreeableness on team performance.

-To analyze the effect of openness on team performance.

-To analyze the effect of conscientiousness on team performance.

- To analyze effect of neuroticism on team performance.

\subsection{Justification:}

The foremost determination of this study is to measure the effect of immense five persona characteristics on team performance. This research will help organizations to know that all employees have different kinds of personality traits and each of them will behave according to his or her personality trait when they are allowed to perform as a team. It will assist HR managers so that they are able to make such strategies so that they are able to retain employees and facilitate them to work together as a team through which organizations will be able to increase productivity and performance.HR managers will be direct beneficiaries and employees as well as other staff will be considered as indirect.

\subsection{Limitations}

Convenience sampling method has been used and data collected thorough the responses of participants employed in Habib Metro Bank Karachi. Due to time and monetary limit large number of sample size cannot be taken. We have chosen Habib Metro Bank as it is easily accessible.

\subsection{Scope}

This research is conducted to find out that employees will be able to work together in a group with different personality traits. As employees of Habib Metro bank will able to give their response as it is easily accessible.

\subsection{Assumptions:}

-All other factors are kept constant.

-All the participants will provide true data.

\subsection{Definitions of key terms:}

- Neuroticism (N) The propensity to have tenseness, concern, unease, poignant unsteadiness, antagonism and unhappiness.

- Extraversion (E) An active move towards the outside globe, together with friendliness, boldness and optimistic emotionality.

- Openness to experience $(\mathrm{O})$ explains the extent, depth, novelty along with intricacy of a person's psychological and empirical life.

- Agreeableness (A): The superiority of individuals' personal relations along a range from empathy and humanity to opposition.

- Conscientiousness (C) perseverance, association, plus inspiration in objective-aimed at actions, in addition to communally agreed inclination power. 
- Team Performance: Group enactment/team performance as the degree to which a group is skillful to meet proven value, price and interval purposes (Gemuenden \& Lechler, 1997); (Schwartz, 1994).

\section{Literature Review:}

\subsection{Personality as A projecting Measure:}

The readings linking team associate persona to group act is scarce. Utmost of the readings that accomplished to occur determine as well as communicate explicit persona characteristics (which comprise a miniature portion of single of the five features) to group act or group contentment. No duplication of several of the consequences exist due to the job condition and the position nature of the trials. An individual reliable, vigilant, detailed, accountable, prearranged, planned, and reliable, exhibiting the aspect of 'Conscientiousness' has been defined as being determined, plus accomplishment-focused (Digman, 1990) (Barrick \& Mount, 1991). In the single workers assortment study, the feature 'Conscientiousness' has been presented to be an effective forecaster of upcoming work performance for all job-related groups (Barrick \& Mount, 1991) (Tett, Jackson, Rothstein, \& Reddon, 1994). Extraversion is illustrated by such qualities as amiability, friendliness, self-assured, and liveliness (Barrick \& Mount, 1991) (Digman, 1990). In separable employee's assortment literature, 'Extraversion' has remained presented to ensure affirmative substance in forecasting upcoming individual work enactment for those professions that have a huge societal module (Barrick \& Mount, 1991) (Tett, Jackson, Rothstein, \& Reddon, 1994).Assumed that an enhancing assignment executed as a group involves numerous public connections amongst the participants, it might be discussed that the aspect of 'Assertiveness' might be connected to the group's enactment for an enhancing assignment. The feature of 'anxiousness' can as well be considered like not having of 'feelings with solidity, otherwise change (which is the degree to which individual shows 'feeling of solidity). 'Anxiousness' is distinguished by attributes for example nervousness, sadness, irritation, discomfiture, touching, plus timidity (Digman, 1990) (Barrick \& Mount, 1991). In the employee's assortment study, 'freedom of solidity was not initiated to be associated with potential work. (Barrick \& Mount, 1991)Assumed that previously a definite doorway of firmness had been achieved by the individual experienced; the level of 'feeling of solidity was not considered pertinent in forecasting work. Though, in the area of collection or groups, both (Mann, 1959)and (Heslin, 1964)asserted that alteration was one of the optimum features in forecasting assembly work. Human beings who get elevated on candidness to practice are distinguished by qualities for instance thoughts, nonconformity, sovereignty, ingenuity, as well as conflicting idea (McCrae \& Costa, 1987). Their skill in mysterious thoughts along with hope in addition to reflection of shared principles (McCrae R. R., 1996).

Persons who are open to novel understandings worth rational topic, are paying attention to remarkable contemplation procedures, in addition are frequently observed as considerable also inventive. It also signifies persons' propensity to be thoughtful, creative, ingenious, plus perceptive. Satisfying persons are unselfish, temperate, liberal, credulous, plus helpful (McCrae \& Costa., 1987) (Costa \& McCrae, 1992). According to (Barrick \& al, "Relating member ability and personality to work-team processes and team effectiveness.", 1998) , cordiality perhaps single of the finest character forecasters of assisting conduct. Those who are usually helpful, agile, kind, plus broadminded are naturally prone to be supportive. In job situations, managers are a usual aim plus recipient of this serving. This is for the reason that managers are most important to workers. Associations among the 'group alignment' of persona concept and group enactment indirectly undertakes that there is a redeeming connection amongst the persona aspect being verified and following group enactment. Specifically, if an aspect of personality is surely coordinated with assignment requirements that low result of particular characters on the aspect can be reimbursed by high result on the similar aspect by other group participants. Here it possibly will demonstrate to be exceptionally narrow and basic interpretation of characters. So in a group the output of a group is depending on the unity of group participants' behaviors (Moos \& Speisman, 1962).

$\mathrm{H}_{\mathrm{o} 1}$ : There is no significant relationship between openness to experience and team performance

$\mathrm{H}_{\mathrm{A} 2}$ : There is a significant relationship between conscientiousness and team performance

$\mathrm{H}_{\mathrm{A} 3}$ : There is a significant relationship between extroversion and team performance

$\mathrm{H}_{\mathrm{A} 4}$ : There is significant relationship between agreeableness and team performance

$\mathrm{H}_{05}$ : There is no significant relationship between neuroticism and team performance

\section{Methodology}

The determination of this exploration is to gauge the result of big five persona characteristics on team performance. The reason is to find out what are the features which facilitate to play a significant part in enabling the employees with different personality traits to perform as a team for their organization. The philosophy related to this research is post positivism as these factors were tested in other context and with different participants. Deductive (From General to Specific) approach has being used for this research as it has been tested with other variables and different factors. In this research mono method will be used for data collection through questionnaires. The time horizon was cross sectional as the data collected only once. The data will be poised 
through primary and secondary sources. Primary data will be composed by asking open/closed ended questions from employees belonging to Habib Metro Bank. Secondary data will be collected through books, internet and articles. We designed the questionnaire in which we have asked employees about the team performance and personality traits, how personality traits have impact on performance and what their insight about it. After that, collected data have been evaluated that which personality traits have key impact on performance. Our targeted inhabitants were both male and female employees of Habib Metro bank. The participants were the employees working in Habib Metro Bank who are literate and are aware about the topic and they also have working experience on the basis of which they will give their point of view and they will be able to fill the questionnaire and they are age bracket fall from twenty five and above. For the valuation of our inhabitants, we referred numerical procedure where margin of fault $(5 \%)$ and confidence interval $(95 \%)$ was supposed, thus our inhabitants assortment was four thousand with sample of three hundred and fifty seven. Reliability will be assessed through pilot testing. Cronbach alpha was calculated through SPSS and its value is 0.865 . Face validity was utilized in which domain specialist checked the questionnaire.

\section{Data Analysis \& Key Findings}

\subsection{Pilot Testing}

For validity check, we went to domain expert and got our questionnaire checked. After validity testing, we have conducted pilot run testing in SPSS through Cronbach alpha, i.e. $\underline{0.865}$ which shows that questionnaire is reliable.

Table 1

\begin{tabular}{|c|c|}
\hline \multicolumn{2}{|c|}{ Reliability Test } \\
\hline Cronbach's Alpha & N of Items \\
\hline .865 & 43 \\
\hline
\end{tabular}

\subsection{Demographics:}

\section{Table 2}

\begin{tabular}{|l|l|l|l|l|}
\hline Gender & Frequency & Percent & Valid percent & Cumulative percent \\
\hline Male & 193 & 53.6 & 53.6 & 53.6 \\
\hline Female & 167 & 46.4 & 46.4 & 46.4 \\
\hline Total & 360 & 100 & 100 & \\
\hline Age & Frequency & Percent & Valid Percent & Cumulative Percent \\
\hline Below 25 & 104 & 28.9 & 28.9 & 28.9 \\
\hline $25-35$ & 204 & 56.7 & 56.7 & 56.7 \\
\hline $36-45$ & 24 & 6.7 & 6.7 & 6.7 \\
\hline $46-55$ & 25 & 6.9 & 6.9 & 6.9 \\
\hline Above 55 & 3 & 0.8 & 0.8 & 0.8 \\
\hline Total & 360 & 100 & 100 & \\
\hline
\end{tabular}



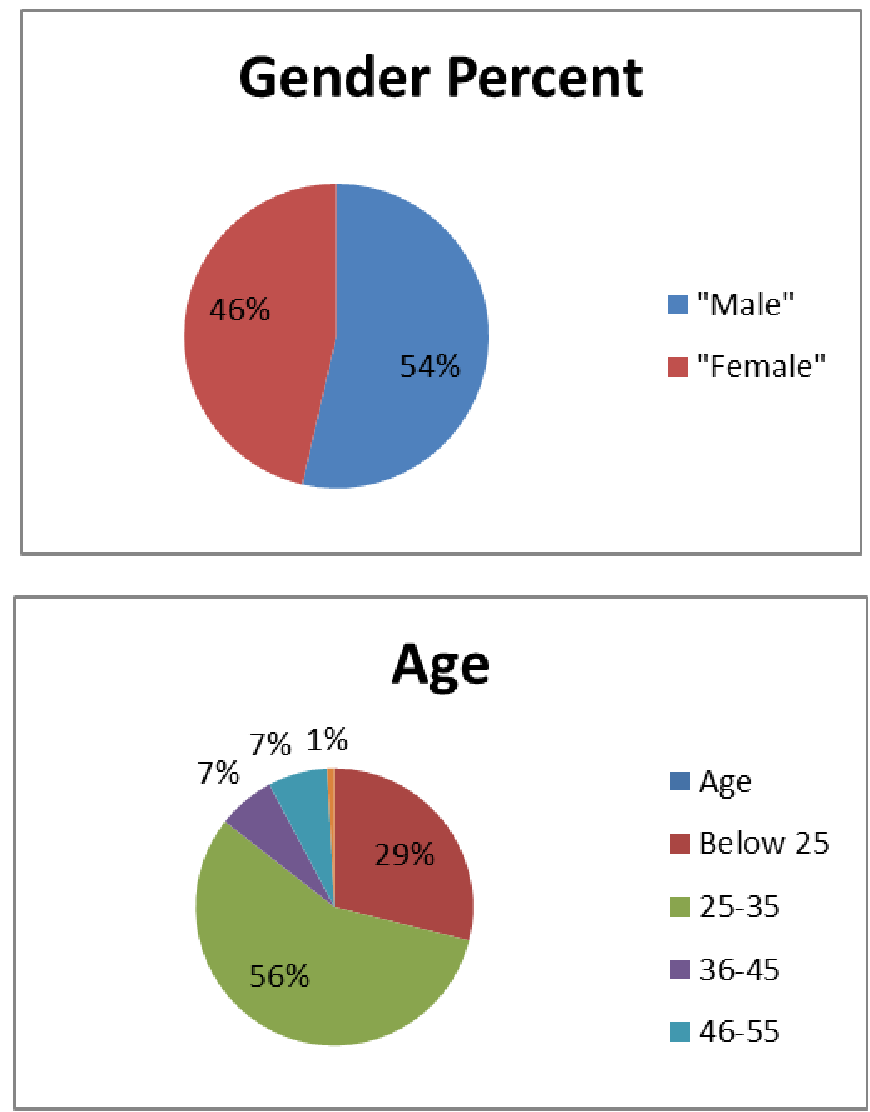

The above pie charts shows three hundred and sixty sample size are valid responses. The table of gender shows about one hundred ninety three i.e. $53.6 \%$ numbers of male employees and one hundred and sixty seven i.e. $46.6 \%$ are female employees of Habib Metro Bank. Similarly, both age pie chart and table of age shows that $28.9 \%$ employees fall in age bracket of below 25 , while $56.7 \%$ fall in $25-35$ age bracket, $6.7 \%$ fall in $36-45$ age bracket, $6.9 \%$ fall in $46-55$ age bracket, remaining $0.8 \%$ fall in age group of above 55 .

\subsection{Cross tabulation:}

Table 3

\begin{tabular}{|l|l|l|l|l|l|l|l|}
\hline \multicolumn{2}{|c|}{} & \multicolumn{9}{c|}{ Age } & Total \\
\cline { 3 - 8 } \multicolumn{2}{|c|}{ Gender } & Below 25 & $25-35$ & $36-45$ & $46-55$ & Above 55 & \\
\cline { 2 - 8 } & Male & 13 & 139 & 16 & 22 & 3 & 193 \\
\hline Total & & 91 & 65 & 8 & 3 & 0 & 167 \\
\hline
\end{tabular}




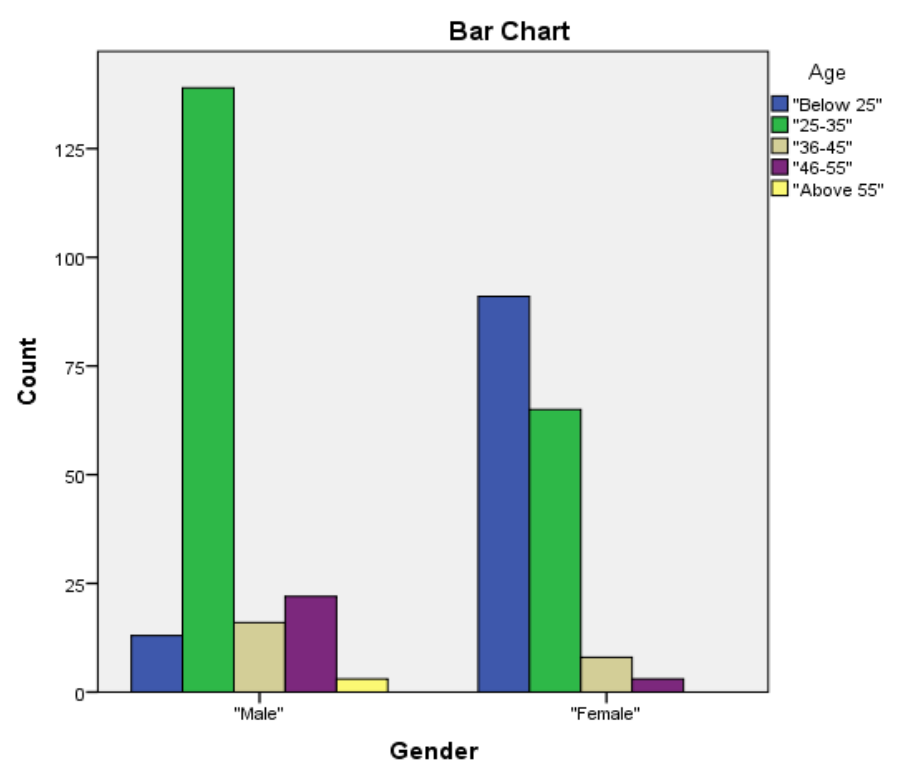

The outcomes of cross tabulations are demonstrating those 25-35 years of male and 25-35 +years of female have participated more in the study.

\subsection{Descriptive Analysis:}

Table 5

\begin{tabular}{|l|r|r|r|r|r|}
\hline & $\mathrm{N}$ & \multicolumn{1}{|c|}{ Minimum } & \multicolumn{1}{c|}{ Maximum } & \multicolumn{1}{c|}{ Mean } & \multicolumn{1}{c|}{ Std. Deviation } \\
\hline Extraversion & 360 & 1.29 & 5.00 & 3.4016 & .67011 \\
\hline Agreeableness & 360 & 1.60 & 4.80 & 3.7472 & .57039 \\
\hline Conscientiousness & 360 & 1.80 & 4.80 & 3.9200 & .54137 \\
\hline Neuroticism & 360 & 1.50 & 5.00 & 3.5389 & .55280 \\
\hline Openness & 360 & 1.80 & 4.80 & 3.8283 & .80443 \\
\hline Team Performance & 358 & 1.81 & 4.50 & 3.1473 & .63477 \\
\hline
\end{tabular}

Mean value of all variables are above 3, that shows most of the participants agree with extraversion, agreeableness, conscientiousness, neuroticism and team performance. Values of standard deviation which is between $0.5-1$ shows that there is less variation in respondent's opinion as the responses are close to mean values.

\subsection{Association (Correlation):}

$\mathrm{H}_{01}$ : There is no significant relationship between openness to experience and team performance

$\mathrm{H}_{\mathrm{A} 2}$ : There is a significant relationship between conscientiousness and team performance

$\mathrm{H}_{\mathrm{A} 3}$ : There is a significant relationship between extroversion and team performance

$\mathrm{H}_{\mathrm{A} 4}$ : There is significant relationship between agreeableness and team performance

$\mathrm{H}_{05}$ : There is no significant relationship between neuroticism and team performance

Table 6

\begin{tabular}{|l|l|l|}
\hline Correlation & \multicolumn{2}{|c|}{ Team Performance } \\
\hline & Pearson Correlation & Sig. (2-tailed) \\
\hline Extraversion & 0.591 & 0.000 \\
\hline Agreeableness & 0.412 & 0.000 \\
\hline Conscientiousness & 0.602 & 0.000 \\
\hline Neuroticism & -0.064 & 0.226 \\
\hline Openness & 0.030 & 0.577 \\
\hline
\end{tabular}

Interpretation of Extraversion: Since significance $=0.000<0.05$ therefore we can conclude that extraversion is associated with team performance furthermore the positive sign indicates that if there are extrovert people in team than team performance will be high. The value of correlation 0.591 indicates that correlation is in acceptable range.

Interpretation of Agreeableness: Since significance $=0.000<0.05$ therefore we can conclude that agreeableness is associated with team performance furthermore the positive sign indicates that if there are agreeable people in team than team performance will be high. The value of correlation 0.412 indicates that correlation is in acceptable range.

Interpretation of Conscientiousness: Since significance $=0.000<0.05$ therefore we can conclude that 
conscientiousness is associated with team performance furthermore the positive sign indicates that if there are conscious people in team than team performance will be high. The value of correlation 0.602 indicates that correlation is in acceptable range.

Interpretation of Neuroticism: Since significance $=0.226<0.05$ therefore we can conclude that neuroticism is not associated with team performance furthermore the positive sign indicates that if there are neurotic people in team than team performance will be low. The value of correlation -.064 shows that neuroticism is negatively related with team performance

Interpretation of Openness to Experience: Since significance $=0.557<0.05$ therefore we can conclude that openness to experience is not associated with team performance. The value of correlation .030 indicates that there is weak correlation between openness to experience and team performance.

\subsection{Causal Relationship (Regression):}

$\mathrm{H}_{\mathrm{A} 6}$ : There is a significant effect of openness to experience on team performance

$\mathrm{H}_{\mathrm{A} 7}$ : There is a significant effect of conscientiousness on team performance.

$\mathrm{H}_{\mathrm{A} 8}$ : There is a significant effect of extroversion on team performance

$\mathrm{H}_{\mathrm{A} 9}$ : There is a significant effect of agreeableness on team performance.

$\mathrm{H}_{\mathrm{A} 10}$ : There is a significant effect of neuroticism on team performance.

Table 7

\begin{tabular}{|l|l|l|l|l|l|l|}
\hline Model & R & R Square & Adjusted R Square & Std. Error of Estimate & F & Sig. \\
\hline 1 & $.716^{\mathrm{a}}$ & .512 & .505 & .44626 & 73.929 & $.000^{\mathrm{b}}$ \\
\hline
\end{tabular}

The table of ANOVA indicates that significance for the model $=0.000<0.05$ and f-value is 73.929 therefore we can accept the alternate hypothesis that all independent variables are causing variation in team performance. The adjusted R-square $=51.2 \%$ therefore $48.8 \%$ variation in team performance is not explained by this model.

Table 8

\begin{tabular}{|l|l|l|l|l|l|}
\hline \multirow{2}{*}{ Model } & \multicolumn{2}{|c|}{ Unstandardized Coefficients } & \multicolumn{1}{c|}{ Standardized Coefficients } & \multirow{2}{*}{ t } & Sig. \\
\cline { 2 - 5 } & \multicolumn{1}{|c|}{$\mathrm{B}$} & Std. Error & & & \\
\hline Constant & .932 & .241 & & 3.863 & .000 \\
\hline Extraversion & .437 & .048 & .462 & 9.019 & .000 \\
\hline Agreeableness & .045 & .051 & .040 & .869 & .385 \\
\hline Conscientiousness & .419 & .057 & .354 & 7.337 & .000 \\
\hline Neuroticism & -.226 & .050 & -.198 & -4.535 & .000 \\
\hline Openness & -.074 & .034 & -.094 & -2.167 & .031 \\
\hline
\end{tabular}

$\mathrm{H}_{\mathrm{A} 5}$ : There is a significant effect of extroversion on team performance

Since significance of extraversion is $0.000<0.05$ therefore we accept alternate hypothesis indicating that there is impact on team performance. Thus, we will not reject alternate hypothesis. Therefore if extroversion is increased by one it will transform 0.437 (43.7\%) in team performance.

$\mathrm{H}_{\mathrm{O6}}$ : There is no significant relationship effect of agreeableness on team performance

Since significance of agreeableness is $0.385>0.05$ therefore we accept null hypothesis indicating that there is no impact of agreeableness on team performance. Thus, we will reject alternate hypothesis. Therefore if agreeableness is increased by one it will not transform 0.045 (4.5\%) in team performance.

$\mathrm{H}_{\mathrm{A} 7}$ : There is a significant effect of conscientiousness on team performance

Since significance of conscientiousness is $0.000<0.05$ therefore we accept alternate hypothesis indicating that there is impact of conscientiousness on team performance. Thus, we will not reject alternate hypothesis. Therefore if conscientiousness is increased by one it will transform $0.419(41.9 \%)$ in team performance.

$\mathrm{H}_{\mathrm{A} 8}$ : There is a significant effect of neuroticism on team performance

Since significance of neuroticism is $0.000<0.05$ therefore we accept alternate hypothesis indicating that there is impact of neuroticism on team performance. Thus, we will not reject alternate hypothesis. Therefore if neuroticism is increased by one it will not transform by $-.226(-22.6 \%)$ in team performance.

$\mathrm{H}_{\mathrm{A} 9}$ : There is a significant effect of openness on team performance

Since significance of openness is $0.031<0.05$ therefore we accept alternate hypothesis indicating that there is impact of openness on team performance. Thus, we will not reject alternate hypothesis. Therefore if openness is increased by one it will not transform by $-.074(7.4 \%)$ in team performance.

\subsubsection{Regression line:}

Team performance $=0.932$ (constant) +0.437 (Beta of Extraversion $)+0.045($ Beta of agreeableness $)+0.419$ (Beta of Conscientiousness) + (-0.226) Beta of Neuroticism + (-0.074) Beta Of openness

\subsection{Discussion}

The purpose of the descriptive study is to discover the impact of big five persona characteristics on team performance/group enactment of workers of Habib Metro Bank. This study is extremely beneficial for HR 
professionals to understand the natural features in worker persona leading to high productivity in establishments where human resource division is essential as well as also for personnel working in banking sector.

The foremost significant finding in the study associates to the conscientiousness feature. It was establish to be a constantly effective interpreter for all work-related groups considered and for all standard categories. Therefore, this feature of personality seems to hit qualities which are vital to the completion of work responsibilities in all occupations. That is, those persons who display qualities related with a robust wisdom of persistence, responsibility, and determination usually achieve superior than those who do not. Comparable conclusions have been described in informative surroundings where associations among marks on this aspect and informative accomplishment (John M \& Takemoto-Chock, 1981) (Smith G. M., 1967) and professional accomplishment (Takemoto, 1979) ensure constantly been described in the sort of .50 to .60. Conscientious workers are determined, tenacious and stable. They are in favor of accomplishment, meticulous, planned and take all the accountability to surpass in what they do. This has also been evidenced in a study that task enactment or work gratification has robust correlation with meticulousness disposition (Schneider M. , 1999). Creative individuals are acute to embrace modification in organizations which support them to be efficacious personnel. Along with, they are agreeable to deliberate innovative concepts and outstanding beliefs, and they practice both optimistic and undesirable sentiments. But agreeing to study them are mediocre forecasters of work gratification as equated to conscientiousness. (Barrick \& Mount, 1991).

Similarly, extroversion was established to forecast the team performance/group enactment comparatively fine. Persistent through our assumptions, extraversion was an effective forecaster for group enactment. Therefore qualities like gregarious, expressive, fluent, self-confident, and energetic will direct to adequate performance.

Correlation for neuroticism is negative. This result might be due to there may not be direct association between emotional Stability and work enactment. (Barrick \& Mount, 1991)

The outcomes for Sociability recommend that it is not a significant forecaster of work enactment or team performance/group enactment. It seems that being polite, confiding, and benevolent has a lesser influence on enactment than being conversational, vigorous, and self-confident.

The above outcomes are somewhat in track with earlier researches on team performance/group enactment and partially in ambiguity with earlier studies. The research of (Biswas, 2008) exhibited that sociability, meticulousness and extraversion have an optimistic association with team performance/group enactment. In this research, openness to experience and neuroticism has insignificant relation with team performance/group enactment. However this study displays that agreeableness, extraversion, openness and conscientiousness have a positive association with team performance/group enactment. Another resemblance between this research and (Biswas, 2008) study was that neuroticism is adversely associated with group enactment. This outcome is also promoted in earlier researches. (Barrick, Bradely, Amy, Kristof, \& Colbert, 2007) (Kichuk \& Wiesner, 1997).

\section{Conclusion and Recommendations: 5.1 Conclusion:}

The purpose of this study is to measure the result of big five personality characteristics on team performance. The reason is to find out what are the features which facilitate to play a significant part in enabling the employees with different personality traits to perform as a team for their organization. The philosophy related to this research is post positivism as these factors were tested in other context and with different participants. Deductive approach has being used for this research as it has been tested with other variables and different factors. In this research mono method will be used for data collection through questionnaires. The purpose of this study was to know how the members of a team having different personality traits will perform together. Founded on the outcomes, the big five persona qualities (openness to experience, conscientiousness, extraversion, agreeableness, emotional stability) play a significant part in impelling employee's enactment in banking sector. The above outcomes are somewhat in track with earlier researches on team performance/group enactment and partially in ambiguity with earlier studies. The research of (Biswas, 2008) exhibited that sociability, meticulousness and extraversion have an optimistic association with team performance/group enactment. In this research, openness to experience and neuroticism has insignificant relation with team performance/group enactment. However this study displays that agreeableness, extraversion, openness and conscientiousness have a positive association with team performance/group enactment. Another resemblance between this research and (Biswas, 2008) study was that neuroticism is adversely associated with group enactment. This outcome is also promoted in earlier researches. (Barrick, Bradely, Amy, Kristof, \& Colbert, 2007) ( Kichuk \& Wiesner , 1997). When performance will increase, it will enhance productivity of the organization .It will also help in retaining the experienced employees due to which turnover will be reduced.

Hence, this study is providing a very valuable understanding for upcoming studies on features that impact on employee enactment in banking sector. 


\subsection{Recommendations:-}

Research was accompanied only on employees of Habib Metro bank; it can also be conducted in other banks to make it more generalizable. Additional private and government segments can be equated in order to discover personality effects on team performance. Trainings must be done to know about the personality type of any individual and jobs must be assigned according to the personality possessed by an individual. Agreeing to the research, the association among persona qualities and team performance/group enactment would be considered with bigger samples in establishments which assistances in enhancement of work associated difficulties and leads to extraordinary progress. On the other hand, the effects of ethnic dissimilarities on the association among persona measurements with team performance can also be available and advance studied.

\section{Bibliography}

Andrew, \& Hargadon. (2003). The Surprising Truth About How Companies Innovate. Boston.

Barrick, M. R., \& al, e. (1998). "Relating member ability and personality to work-team processes and team effectiveness.". Journal of applied psychology.

Barrick, M. R., \& Mount, M. K. (1991). The big five personality dimensions and job performance: a meta - analysis.

Barrick, M. R., Bradely, B. H., Amy, L., Kristof, B., \& Colbert, A. W. (2007). The moderating role of top management team interdependence: Implications for real teams and working groups. Academy of Management Journal, 544-557.

Barrick, M., \& Mount, M. (1991). The big five personality dimesnsions and job performance: A meta-analysis. Personnel psychology, 44, 1-26.

Biswas, S. N. (2008). Personality, generalized self-efficacy \& team performance: a study of rural development teams. Indian Journal of Industrial Relations.

Costa, P. T., \& McCrae, R. R. (1992). "Normal personality assessment in clinical practice.

Digman, J. M. (1990). Personality structure: Emergence of the five-factor model. Annual review of psychology, 417-440.

Gemuenden, H. G., \& Lechler, T. (1997). Success factors of project management: the critical few-an empirical investigation." Innovation in Technology Management-The Key to Global Leadership. 375-377.

Goldberg, L. R. (1990). "An alternative" description of personality": the big-five factor structure." . Journal of personality and social psychology.

Heslin, R. (1964). Predicting group task effectiveness from member characteristics." .

Hofstee, W. K. (1998). "A comparison of Big-Five structures of personality traits in Dutch, English, and German.". Journal of Work and Organizational Psychology, 15-31.

John M, D., \& Takemoto-Chock, N. K. (1981). Factors in the natural language of personality: Re-analysis, comparison, and interpretation of six major studies. 149-170.

Kichuk, S. L., \& Wiesner, W. H. (1997). The Big Five personality factors and team performance: implications for selecting successful product design teams . Journal of engineering and technology management. , 195221.

Mann, R. D. (1959). A review of the relationships between personality and performance in small groups.

McCrae, R, R., \& John, O. P. (1992). An introduction to the five - factor model and its applications. Journal of personality, 175-215.

McCrae, R. R. (1985). "Updating Norman's" adequacy taxonomy": Intelligence and personality dimensions in natural language and in questionnaires. "Journal of personality and social psychology.

McCrae, R. R. (1996). Social consequences of experiential openness." .

McCrae, R. R. (1997). "Personality trait structure as a human universal.".

McCrae, R. R., \& Costa, P. T. (1987). Validation of the five-factor model of personality across instruments and observers. Journal of personality and social psychology.

McCrae, R. R., \& Costa., P. T. (1987). Validation of the five-factor model of personality across instruments and observers. Journal of personality and social psychology.

Moos, R. H., \& Speisman, J. C. (1962). Group compatibility and productivity. Abnormal Social Psychol, 190196.

Norman, W. T. (1963). Toward an adequate taxonomy of personality attributes: Replicated factor structure in peer nomination personality ratings. Toward an adequate taxonomy of personality attributes: Replicated factor structure in peer nomination personality ratings.

Pfaff, Elizabeth, \& Huddleston, P. (2003). Does it matter if I hate teamwork? What impacts student attitudes toward teamwork. Journal of Marketing Education, 37-45.

Robertson, I. a. (1998). "Personality and work behaviour." European Journal of Work and Organizational Psychology. 321-340.

Schneider, M. (1999). The relationship between personality and job settings to job satisfaction. Dissertation 
abstracts international: section B: science and engineering, 59, 6103.

Schwartz, S. H. (1994). Beyond individualism/collectivism: New cultural dimensions of values. Sage Publications, Inc.

Smith, G. M. (1967). Usefulness of peer ratings of personality in educational research. Educational and Psychological Measurement, 967-984.

Srivastava, S. (2011). Measuring the Big five personality factors.

Takemoto, N. (1979). The prediction of occupational choice from childhood and adolescent antecedents.

Tett, R. R., Jackson, D. N., Rothstein, M., \& Reddon, J. R. (1994). Meta Analysis of personalit- Job performance relations:A reply to ones, Mount, Barrick, and Hunter. Personnel Psychology, 157-172.

Thomas, Sarah, \& Busby, S. (2003). Do industry collaborative projects enhance students' learning?. Education+ Training, 226-235.

W, J. D., \& Jhonson, R. T. (1999). Making cooperative learning work." Theory into practice . 67-73. 